I find it interesting to note that the ICCA Journal has published many artıcles whose main theme is not computer chess, but relate to general aspects of game playing, especially heuristic searching methods I thınk the ICCA Journal should acknowledge in its arms and scope that there are various problems relating to heurıstic game playing that can be addressed through strategic games other than Chess I will briefly list some such games and problems

The game of Go is an example where the 'brute-force' method, which has been so successful in Chess, does not seem to work Makıng progress in artificial Go demands heurıstic searching technıques that are much more selectıve than current methods and a much better understanding of how to encode knowledge, which may be local to independent parts of the game tree The game of Bridge is an example of a game with imperfect information, as opposed to Chess in which the information is perfect Again, new heuristic search methods need to be developed and explored to take into account the numerous eventualities The game of Backgammon is an example of a game with chance moves, as opposed to Chess which has no chance element Although strong programs have recently been developed using temporal differencing techniques, there is still the open problem of developing novel search methods for such games Finally, Diplomacy is an example of a game with $\mathrm{N}$ players, where $\mathrm{N}$ is greater than two, as opposed to Chess where there are only two players Such games pose a variety of new challenges such as modelling the negotiation between players and searching $\mathrm{N}$-person game trees with large branching factors whose evaluation function is not, in general, zero-sum Here mathematical game theory may prove to have a considerable impact on the direction taken by researchers

I still thınk that computer chess is a unifying theme for a large number of problems in this area and as such I would not like to see the ICCA Journal change its name In addition, Chess provides a central example of what we should aim at with respect to other games I strongly feel that in order to keep abreast with new developments and challenges, and also encourage new research in the area of heuristic game playing, the ICCA should broaden its aims and scope to include other strategic games apart from Chess

\title{
ICCA TOURNAMENT RULES REVISITED
}

\author{
Ernst A Helnz' \\ Karlsruhe, Germany
}

Dear ICCA Board and Fellow ICCA Members,

Since my first participation in an ICCA tournament (as member of the DARKTHOUGHT team during the $8^{\text {th }}$ WCCC in Hong Kong, 1995) I have had the same mixed feelıngs about the definitions of "amateur vs professional' as anybody else Therefore, I sent an initial proposal to David Levy on July 31, 1995, intıoducing "pure" and "semı" subcategories for both amateurs and professionals Unfortunately, nothing ever came thereof although the proposal surely had some merts

Right now, however, tımes have changed and so has my opınion as for the dreaded "amateur vs professıonal" case Moreover, anotheı important issue has emerged - namely "kıller book lines bustıng commercial programs " Because any live tournament will be very limited in its possible number of rounds, I personally teel this issue to be of great importance in order to ensure future participation of commercial programs in ICCA events

In the following, I propose new solutions to both of the above while hopıng for your comments and fruttul discussions 1

\footnotetext{
1 School of Computer Science (IPD), University of Karlsruhe, P O Box 6980, D-76128 Karlsruhe, Germany Ema1l heinze@1ra uka de
} 


\section{Amateurs and Professionals}

First of all, I propose to finance ICCA events solely by sponsor and other avalable ICCA money thus elıminating all entrance fees' The compulsory ICCA membership for all participants remains untouched thereby

With no more entrance fees, the necessity of different amateur, manufacturer, and professional titles being awarded at microcomputer events has gone Therefore, I propose to solely award overall titles

Instead of distınguishing between amateurs and professionals, I propose to focus on the cential subject of this distinction commercial interest

Definition: Anybody who conducts, is about to conduct, or is employed by somebody conducting commercial activities that might benetit from his activities related to computer chess has a commercial interest in computer chess

This definition of commercial interest clearly subsumes the authors and distributors of all commercial and shareware programs as well as people like the DEEP BLUE team hired for doing computer chess to benefit their employers' commercial activities Furthermore, it subsumes those people whose commercial interest in computer chess according to the definition starts in the near future, e g, shortly aftel winnıng an ICCA tournament (how long "shortly" actually means is open to debate, my suggestion runs from $1 / 2$ to 1 year)

All participants with commercial interests in computer chess are never eligible for financial support by the ICCA during any of its events In case of participants starting their commercial interests in computer chess within $1 / 2$ to 1 year after an event they received financial support for by the ICCA, the according grants must be fully repard

All participants without commercial interests in computer chess should receive tinancial support in decreasing order of estımated playing strength Of course, everybody and especially university affilıates are encouraged to apply for other sources of financial support in order to save the ICCA as many expenses as possible

Last but not least, participants with commercial interests could possibly be made to pay a tee to the ICCA if thelı advertisements and/or products refer to thell participation and/or titles in ICCA events

\section{Opening Play}

In order to prevent kıller book lines (especially tuned against commercial programs) from intoleıably distortıng the result of an ICCA event, I propose the following scheme of random opening play

1 White chooses his first move and then Black his reply

2 White chooses an ECO opening system reachable trom the current position

3 Black chooses an ECO opening system reachable fiom the choice White made in step (2)

4 From the ECO opening system of Black's choice in step (3) a random position no deeper than 8 moves from the startıng position with WTM and roughly equal play according to general openıng theory is chosen

5 The game starts from the position chosen in step (4) with both programs being allowed to use all their databases

A much simpler scheme which does not allow for the choice of special opening systems by the opponents would be directly to determine a random position according to step (4) at the start of the game

Furthermore, I suggest to extend all ICCA events to at least 7 rounds, of course, a 9 to 11 1ound WCCC would be even better' 